course of this old river-valley over the platform the channel has, to a great extent, been choked up and nearly obliterated by the deposit of sediment constantly going on for long ages; but along this part of its course, owing doubtless to the force of the tidal currents due to the narrowness of the channel, the sediment has apparently not been able to accumulate; hence the well-defined banks of rock which the soundings disclose. As regards the submerged channels of the existing rivers entering the Atlantic westwards, only faint indications can be obtained from the soundings; nor is this surprising when we recollect that the North Sea, the Irish Channel, and portions of the ocean bordering the north-western coasts of the British Isles have been covered in part by land ice, and altogether by the muddy waters of the later glacial seas, giving place to those of the present day; the mud, sand and shingle thus deposited have sufficed to cover the old floor of the platform for many feet in depth in most places, and to fill up the channels of the streams formed during earlier emergence. The total distance from north to south through which these observations extend is about 500 miles. I hope to be able to return to the subject later on. EDWARD HULL.

\section{The Use of Compressed Coal Gas.}

IT may be of interest to users of the limelight to put on record the following occurrences.

A 40-feet cylinder was filled with coal gas at a pressure of 120 atmospheres by a leading London firm on March I 5, I897; a small quantity was used, and the cylinder stood till October 9. It was then used for a mixed jet, and at the end of half an hour the light began to decrease, and in another quarter of an hour practically no gases were issuing. On relighting the jet the light was found perfect, and the fault was ascribed to the Beard's regulator.

The cylinder was again used on March 5 last, and again after half an hour the light began to fail ; but on turning the taps full on something audibly blew out of the nozzle, and the light was perfectly restored.

The lime blackened excessively: while white-hot, the "hydrogen" was turned off and the oxygen allowed to play on it, when the deposit turned a brilliant orange-red.

The coal gas was then passed through a glass tube gently heated in a Bunsen flame - a copious metallic mirror which gave the test for iron was formed.

It seems probable that the jet was choked by the decomposition of iron carbonyl at the high temperature. In any case there is an obvious disadvantage in storing for a considerable time compressed coal gas in steel cylinders, altogether apart from the possible damage to the cylinders, which has been shown to be small.

Harrow, March 19.

C. E. ASHFORD.

\section{THE SCIENCE BUILDINGS AT SOUTH} KENSINGTON.

SINCE the nation acquired, a good many years ago now, a plot of ground from the Royal Commissioners of the Exhibition of $185 \mathrm{I}$, at a cheap rate, on which to erect buildings to foster teaching and research in Science and Art, there have been many schemes put forward, but nothing done, till at last the teaching of Science has become desperate. The Government have known this fully, and a few years ago plans were designed to bring to a head the various schemes by erecting Science buildings on the west side of Exhibition Road, and the Art buildings on the east side, an allocation of the spare land which had been accepted in principle by everybody.

But now it appears there has been a sudden volte face. Seeing that at the present moment Art does not require all the space at its disposal on the east side, the interstices are to be filled up with certain of the science buildings as we gather from the statement made by the First Commissioner of Works, on Thursday last "The Government asked for the large sum of $800,000 l$. for the completion of the buildings at South Kensington in connection with Science and Art. He was quite certain that the Committee would admit that the settlement of this question had been demanded both by the House and by the public for many years past. In 189 I the decision was come to to proceed with the building to complete the accommodation for the Art Museum, and for housing the administrative departments of Science and Art. Plans were accordingly prepared by $\mathrm{Mr}$. Aston Webb, and accepted, for a building to occupy the land on the south side of the Museum facing the Cromwell Road ; but the sources at the disposal of Chancellors of the Exchequer, on both sides of the House, unfortunately did not permit of the grant of the necessary funds, and the scheme had since then been in abeyance. Since that scheme was formulated, and partly in consequence of the report of the Commission on Secondary Education, it was in contemplation to move to the Education Office the secretariat of the Science and Art Department, and further-in accordance with the recommendation of the Select Committee of last year on the South Kensington Museum-it was decided to remove the official residences and certain other temporary buildings, which were a source of danger from fire. With this additional space at disposal, it would now be possible to provide on the eastern side of Exhibition Road the necessary accommodation for both Science and Art. It was, therefore, intended to build, in addition to the building proposed in $189 \mathrm{I}$, further buildings which would complete the frontage on the Cromwell Road and Exhibition Road sites; and, in the opinion of the Government, that would amply meet the requirements of both branches for many years to come."

On this proposal the Times remarks :-

"How far these projects, which the Government regard as all that can be reasonably demanded, will be satisfactory to those who take more than an official interest in the matter it would be premature to speculate."

We do not think it "premature" to state that it is to be hoped that the Government before they go further in this matter will obtain some opinions from men of science. The suggestion appears little short of disastrous, having regard for the future representation of scientific teaching and illustrations in our National Institutions, for surely the Empire will outlast another century. These remarks are not made because the sum asked is too little, for we do not believe a Committee, say of the Royal Society, or the President and Council of the Society itself, appointed to consider the matter, would see its way to spend more than $250,000 l$. to cope with the present needs of Science.

\section{SKIAGRAPHY AFTER INJECTION OF THE} BLOOD VESSELS WITH MERCURY.

$T O$ elucidate the relations of the various opaque structures of the body to one another whilst undisturbed by the processes of dissection, is one of the numerous uses to which skiagraphy has been applied.

It is obvious that this process may be extended to the blood vessels in the dead body by filling them with some medium which is opaque to the $\mathrm{X}$-rays, and in this way their relative situations to each other and to the bony skeleton may be studied with facility. Various experimenters have occupied themselves with the task of producing such skiagraphs, and amongst a considerable number who have obtained successful pictures may be mentioned Dutto, Raw, and Remy and Contremoulins, the former of whom employed a plaster injection mass, the latter one of wax in which bronze powder was suspended.

These results, though sufficiently encouraging, were not wholly satisfactory, and one of us (H. J. S.) determined to follow out a method which he had devised before he became acquainted with the work of other observers, and in which metallic mercury had been selected as the substance to be injected. The results of our experiments with it have been most satisfactory, and it seems probable that with the greater experience which we have now gained in the methods of carrying out the

NO. 1482 , VOL. 57$]$ 
details of the process, still better work may be done than has yet been accomplished.

The plan which has been adopted is very simple. The blood vessels of the part to be injected are well washed out with a solution of six parts of common salt in a thousand parts of water, and the mercury is then injected by inserting into the principal artery a canula connected with a small reservoir of the metal by a piece of rubber tubing. Care must be exercised to prevent the presence of air in the tubing or canula, and the mercury should be injected at a moderately low pressure, which naturally varies in different cases, but as a general rule may be taken at about 30 to $50 \mathrm{~mm}$. of mercury. If the pressure is excessive there is considerable risk that the resistance

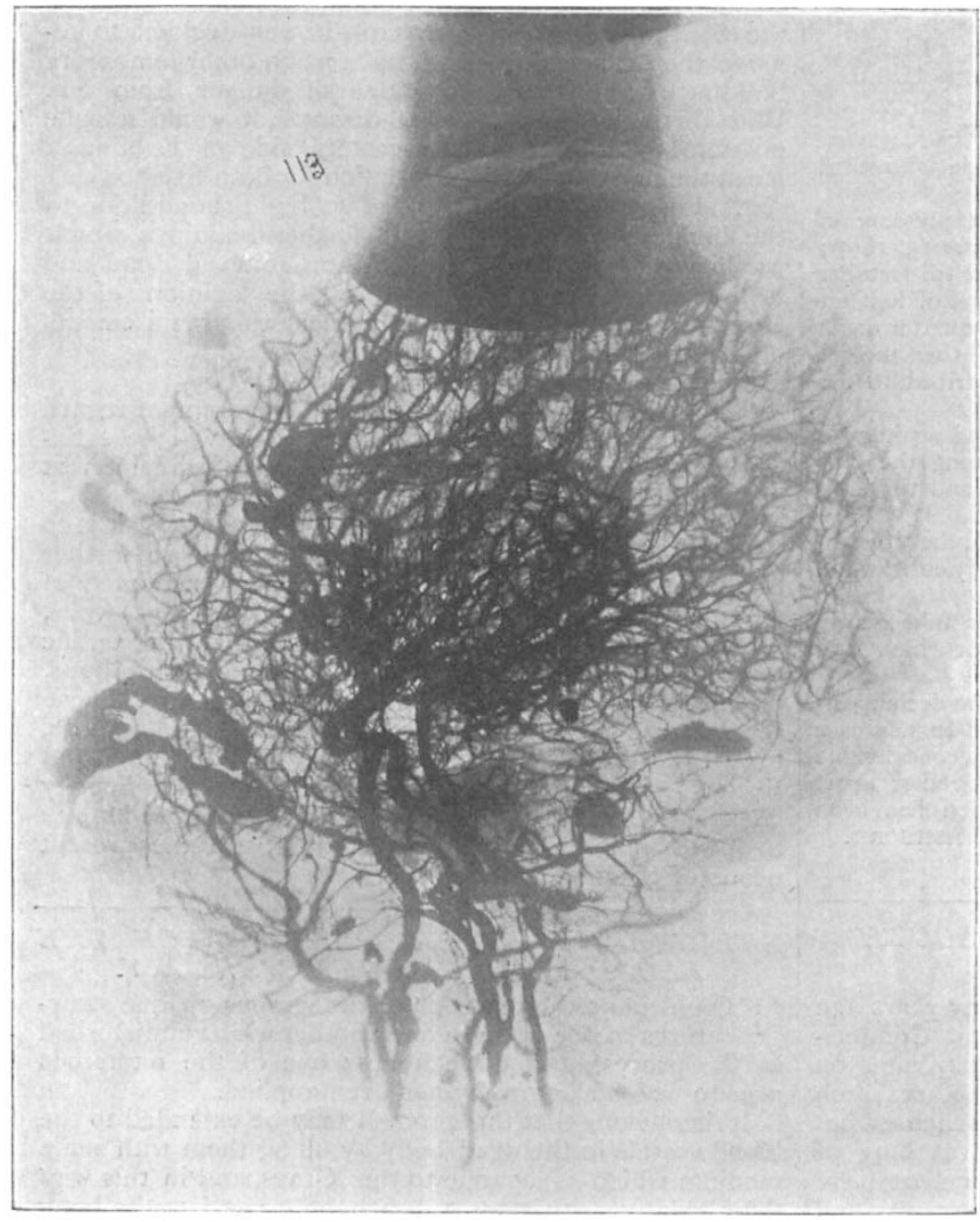

FIG, I.--Arteries of head and brain in a child.

which the capillaries offer to its advance will be overcome, and the veins will be filled as well as the arteries. One very important detail is that the injected specimen should be moved as little as possible after the injection has been effected, as any shaking or change of position is apt to cause breaks to occur in the column of mercury, and thus to interfere with the success of the skiagraph.

We have also found that if the specimen has to be kept for some time before the injection is made, one can preserve it very satisfactorily by filling the blood vessels with a 5 per cent. solution of formalin, which in no way interferes with the subsequent injection, except that it lessens somewhat the calibre of the vessels.

NO. I 482 , VOL. 57$]$
The skiagraphs have been taken in the ordinary way; the authors have employed a ro-inch spark "AppsNewton " coil, and, as a rule, ordinary focus tubes supplied by Mr. Newton, which they have found very satisfactory. Of the illustrations which accompany this paper, Fig. I represents the arterial system of the head of a child. The brain is in situ within the cranium, and the whole is injected through the carotid artery in the neck. The very abundant blood supply to the basal ganglionic masses of the brain is well shown, and it is interesting to note the great tortuosity of the internal carotid arteries as they pass through the base of the skull, by which the force of the sudden rise of blood pressure on the advent of the pulse wave is reduced so far as to prevent an undue strain being thrown on the delicate structures within the cranium. In order to prevent the escape of mercury through the several vessels in the neck, the head was placed upside down upon a small beaker, whose shadow appears in the photograph: where large vessels had been severed, clamp forceps were applied.

The other illustration (Fig. 2) shows the result of an injection of the branches of the system of the superior vena cava. The subject in this case was a young child, and the incomplete ossification of the bones, especially near the joints, may be incidentally noted

In this instance the body was placed lying on its back on the photographic plate, whilst the Röntgen lamp was fixed in front of the chest ; and therefore the anterior part of the bony skeleton is rendered indistinct, whilst the vertebral colunin and posterior portions of the ribs are relatively prominent. The injection has filled the main branches of the superior caval vein and the spinal veins, and it has penetrated also into the right auricle and ventricle, from which it has reached the larger divisions of the pulmonary artery.

It must be remembered, in identifying the various structures in the photograph, that when a print is taken from a negative the relations of the parts are reversed as in a mirror image, and thus what is really on the righthand side in the specimen appears on the left in the print, and vice versâ. This can, when desired, be obviated either by producing the print by the single transfer carbon process, or by taking the original skiagraph with the film side of the negative furthest from the subject. In this case, since glass considerably obstructs the passage of the X-rays, the negative should be on a celluloid support, and the sensitised surface may be laid upon a fluorescent screen. When this is done, the rays after having penetrated the film are still further utilised by inducing fluorescence of the screen, which in its turn acts on the emulsion of the negative. The result of the mancuvre, though somewhat shortening the length of exposure, seems to render the resulting impression rather less sharp in its definition.

A point which must impress any one who looks at these photographs is the extraordinary vascularity of the tissues of the body, and one might reasonably wonder how comparatively small wounds, to say nothing of the large and deep incisions which are required in the course 
of many surgical operations, do not inevitably lead to the death of the sufferer by hemorrhage. The reply to this is, that did the prevention of hæmorrhage depend solely on the efforts of the surgeon, there is little doubt that even small wounds would prove inevitably fatal; but provision has been made by nature to meet the emergency, and the bleeding is largely stopped by what is known as the natural arrest of hæmorrhage.

It is not possible to describe this process in detail in the present paper, but the main elements involved are the fact that blood on escaping from the vessels tends to coagulate, and so forms a plug which prevents further escape, and that the severed vessel retracts up its sheath so that the plug is more efficiently supported, whilst the diameter of the vessel is itself greatly reduced by the contraction of the muscular elements in its walls. By these means the blood flow is temporarily checked, and as the wound gradually heals, secondary changes occur in the cut vessels which lead to their permanent occlusion.

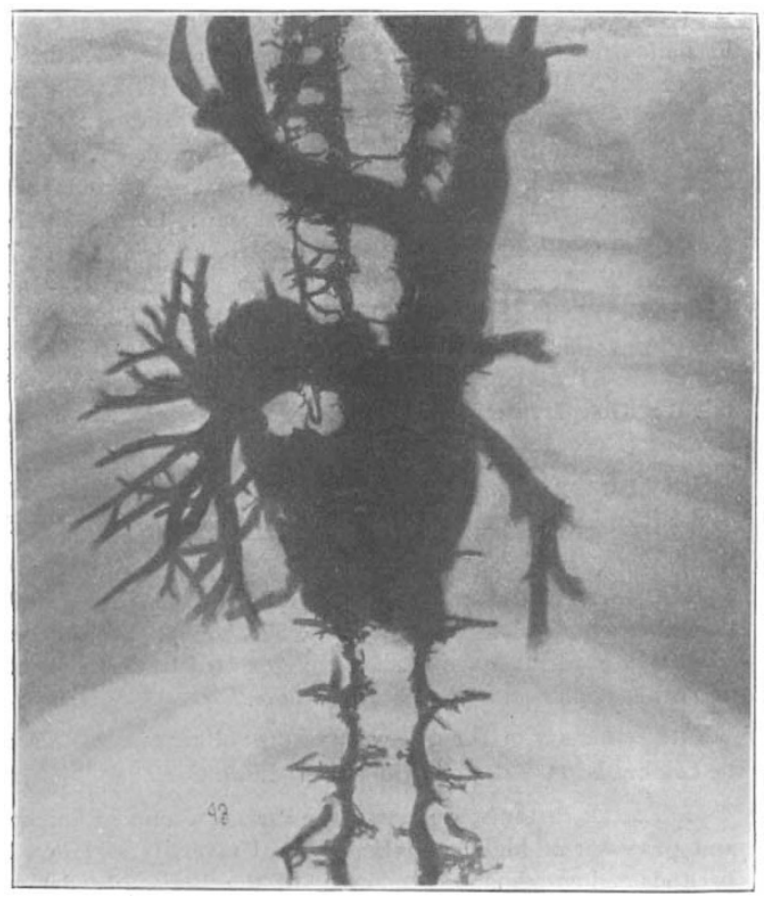

FIG. 2.-Injection of veins in chest.

Another fact that is well illustrated in such skiagrams is the extreme freedom of anastomosis between many of the smaller vessels which arise at different points of the chief arteries. It is this system of anastomosis which permits surgeons to ligature the main artery of a limb without running serious risk of mortification following the operation; as the blood; unable to pass by its ordinary channels, dilates the smaller vessels which bridge the occlusion, and thus establish an efficient collateral circulation in the course of a brief period after the ligature has been applied. H. J. STILES.

H. RAINY.

\section{SIR HENRY BESSEMER, F.R.S.}

THE death of Sir Henry Bessemer, announced last week as we went to press, removes a leading representative of the world of applied science, and one whose inventions.revolutionised a manufacturing process.
Henry Bessemer was born in 1813 at Charlton, in Herts, and was thus eighty-five years of age at the time of his death. From his father, who was an artist and a member of the French Academy of Sciences, he seemed to have inherited certain artistic tendencies, for at an early age he showed a fondness for modelling and designing patterns. He soon, however, turned his attention to other matters, and began the long series of inventions which carried him on to fortune. His success commenced with the invention of a means of manufacturing bronze powder or "gold" paint from Dutch metal. This invention laid the foundation of his fortune, and it was the profits of the manufacture of the bronze powder which enabled him to carry on experiments in the metallurgical process which bears his name.

Bessemer's first experiments to improve the quality of iron were made in 1855 . He was not an iron manufacturer when he began his work, neither was he a metallurgist. But he possessed the true instincts of an investigator, for he was quick to observe and sound in lis deductions; and the man who possesses and utilises these qualities is a man of science, whether he has had a systematic training in theoretical principles or not. His own account of the observations and reasoning which led to the idea of the Bessemer process is interesting. While making experiments with iron in the open-hearth furnace, the following incident occurred :-

"Some pieces of pig iron in one side of the bath attracted my attention by remaining unmelted despite the great heat of the furnace, and I turned on a little more air through the fire-bridge with the intention of increasing the combustion: on again opening the furnace door after an interval of half an hour, these two pieces of pig still remained unfused. I then took an iron bar with the intention of pushing them into the bath, when I discovered that they were merely thin shells of decarbonised iron, thus showing that atmospheric air alone was capable of wholly decarbonising grey pig iron, and converting it into malleable iron without puddling or other manipulation. It was this which gave a new turn to my thoughts, and after due consideration I became convinced that if air could be brought into contact with a sufficiently extensive surface of molten crude iron the latter could rapidly be converted into malleable iron."

On August 13, 1856, Bessemer read a paper at the Cheltenham meeting of the British Associat: 1 , entitled "The Manufacture of Malleable Iron and Steel without Fuel, this being the first account that appeared shadowing forth the important manufacture since known as the Bessemer process. The paper, however, was not printed in the Association's Report for 1856, and the title, where mentioned, it may be noted, is quoted without the word "malleable." It was followed, in 1865 , by a long communication, read at the Birmingham meeting, "On the Manufacture of Cast Steel; its Progress and Employment as a Substitute for Wrought Iron." Sir W. (now Lord) Armstrong, the President of the Section, in referring to it, remarked as follows:- "The paper from Mr. Bessemer upon steel cannot fail to be highly valued by the Section. The growing importance of this material, and its rapidly extending sphere of usefulness, have attracted attention in a special degree to the question of economy in its production; and certainly no one has contributed so largely as Mr. Bessemer to our advance in this direction."

The first honorary recognition of the importance of the Bessemer process in this country was made by the Institution of Civil Engineers in 1859 by the award of the Telford medal. In 187 I-73 he was President of the Iron and Steel Institute, and in 1872 he received the Albert medal of the Society of Arts "for the eminent services rendered by him to Arts, Manufacture, and Commerce, in developing the manufacture of steel."

In 1874 he was a member of a Committee appointed to

NO. 1482 , VOL. 57$]$ 